\title{
The portfolio allocation paradox: An investigation into the nature of a very strong but puzzling relationship
}

\author{
PAUL V. WARWICK ${ }^{1} \&$ JAMES N. DRUCKMAN ${ }^{2}$ \\ ${ }^{1}$ Simon Fraser University, Canada; ${ }^{2}$ Northwestern University, USA
}

\begin{abstract}
Perhaps the strongest empirical finding in political science is 'Gamson's Law': the near-perfect relationship that exists in parliamentary systems between a coalition party's seat contribution to the government and its quantitative allocation of cabinet portfolios. Nevertheless, doubts remain. What would happen if the salience or importance of the various portfolios was also taken into account? Should it not be the case that payoffs correspond with bargaining power rather than seat contributions? And perhaps most significantly, would addressing these issues produce evidence that the parties designated to form governments extract disproportionately large payoffs for themselves, as predicted by 'proposer' models of bargaining? Utilizing the results of a new expert survey of portfolio salience in 14 Western European countries, the authors of this article explore each of these questions. Their basic finding is that salience-weighted portfolios payoffs overwhelmingly mirror seat contributions, contra proposer models and any other models based on bargaining power. The article concludes with a discussion of the implications for formal models of bargaining.
\end{abstract}

The key defining feature of parliamentary democracy is the dependence of governments on the willingness of legislative majorities to support, or at least to tolerate, their existence. In most parliamentary systems, this condition places a premium on coalition building and maintenance since single parties can seldom assume and retain power on their own. A crucial issue that parties must resolve when forming coalition governments is how to allocate the resources of government - specifically, control over government portfolios among themselves. As Laver and Schofield (1990: 164-165) observe, these payoffs 'represent the bottom line of the political process' in parliamentary regimes.

Notwithstanding its centrality to coalition governance, the study of portfolio allocation is characterized by a striking paradox. On the positive side, it has yielded one of the strongest empirical relationships documented in the social sciences: the nearly one-to-one linkage between the proportion of legislative seats a coalition party contributes to the total controlled by the government and the share of cabinet portfolios it receives in that government. Indeed, so strong is the relationship between 'seat shares' and 'portfolio shares', as we 
shall term them, that it has come to be known as 'Gamson's Law' - a rare distinction this side of the natural sciences. Yet surprising as it may seem, the demonstration of so powerful a relationship has not precluded the expression of major doubts concerning both the dependent and independent variables, doubts serious enough to becloud the theoretical import of the relationship. This raises the intriguing possibility that what is arguably the strongest relationship uncovered by political scientists is fundamentally wrong.

If portfolios and the policy influence they provide are the payoffs in the coalition formation game, then the doubt hanging over the dependent variable is evident: it ought to reflect not just the numbers of portfolios each cabinet party receives, but also their varying degrees of importance or salience. To treat the prime ministership as of equal value to control over the Ministry of Sports and Leisure, for example, is clearly a gross mischaracterization of reality in extant parliamentary systems. While the numbers of portfolios allocated to the member parties of a coalition government can be easily determined, however, the measurement of the value or salience of each of these portfolios is an entirely different matter. Only very recently has any systematic attempt been made to take portfolio salience into account when testing the relationship (Warwick \& Druckman 2001), and the estimation of portfolio salience in that study, for want of better alternatives, depended on assumptions that might be termed 'heroic'.

No such measurement issue plagues the independent variable since the prevalence of party discipline in parliamentary systems means that, with few exceptions, seat shares accurately reflect the relative amounts of legislative support that parties can deliver to their governments. Rather, the doubt in this instance is a theoretical one: it concerns whether this is the appropriate way to conceptualize the resources for which these parties receive compensation. Specifically, might it be the case that they are rewarded not according to the legislative seats they control, but rather according to the bargaining potential or strength they wield? While a party's bargaining strength - that is, the extent to which it is pivotal in forming winning or minimal winning coalitions - is related to its legislative size, the connection is far from perfect. The simplest case where the concepts diverge occurs in three-party legislatures where all parties have less than half the seats: although the parties can vary considerably in size, each party may be deemed to have the same bargaining power and hence an equal claim on cabinet portfolios by virtue of being pivotal in the same number of winning or minimal winning coalitions (i.e., two).

These concerns command attention not just because of the importance of establishing the correct specification for so strong a relationship, but also because they may hold the key to resolving what has emerged as a fairly weighty theoretical puzzle. An implication of the tendency for portfolio allo- 
cations to mirror seat shares is that it does not leave much room for the party leader who is invested with proposal power in a formation situation - known in the parliamentary literature as the 'formateur' - to allocate to his or her own party more than its proportional share of the total payoff. If the parties of formateurs receive no more than their seat shares would warrant, however, it would appear to fly in the face of a broad class of proposal-based or 'proposer' models of bargaining whose fundamental implication is that proposers should be able to exploit their privileged position for their own benefit (e.g., Baron \& Ferejohn 1989; Harrington 1990).

The likely absence of any pronounced tendency for the formateur's party to receive more portfolios than its seat share would warrant need not prove devastating for proposer models, however. It may be the case that the 'rent' that formateurs extract is qualitative rather than quantitative; in other words, the formateur's party, although not receiving a disproportional number of portfolios, may take its share from among the more valuable portfolios. (It is noteworthy in this regard that successful formateurs almost always assume the top position: the prime ministership). Alternatively, the evidence may fail to match the expectations of proposer models because resources have been measured by seat shares instead of bargaining power. In particular, a formateur advantage may emerge if seat shares are replaced in the specification by 'voting weights', the standard currency for measuring resources in noncooperative voting models. Thus, the answer to the 'disconnect' between theory and evidence may lie at either end of the empirical relationship.

This article proposes to tackle the paradox of portfolio allocation from both vantage points. To assess portfolio salience, we have conducted surveys of experts in 14 West European countries in which respondents were asked to provide cardinal ratings of the cabinet portfolios in their countries. These ratings, which (with suitable extensions) cover more than 95 per cent of the portfolios held in postwar democratic governments in these countries, make possible the first comprehensive calculation of salience-weighted portfolio payoffs in a broad range of governments. To capture the possibility that bargaining power rather than seat share is the relevant causal factor, we have also calculated the voting weights for each cabinet party in the various postwar democratic governments in these systems as well as their scores on a variety of bargaining power indices. These data will enable us both to implement a fundamental re-assessment of Gamson's Law that takes both the quantity and the quality of portfolio allocations into account, and bring that law into confrontation with a major class of non-cooperative bargaining models that generate very different expectations. In this manner, we hope to untangle the portfolio allocation paradox and cast some light on the larger theoretical issues it raises. 


\section{The study of portfolio allocation: Disputes, problems and remedies}

Understanding the process of portfolio allocation is central to understanding parliamentary governance because, in the final analysis, portfolios are what the parliamentary game is about. It is not just that they provide office benefits to the party leaders that hold them and perhaps also patronage resources for party supporters. Nor is it simply that control over a portfolio means control over a myriad of smaller intradepartmental decisions that do not need cabinet approval. For many of the larger issues, cabinet ministers are in a position to act as 'gatekeepers', preventing proposals they oppose from being brought to the cabinet and fashioning those that they choose to bring forward to suit their own preferences. While most observers would agree that the need to accommodate coalition partners' places limits on this gatekeeping capacity, this consideration must be evaluated in its larger context: the degree of constraint on the individual minister largely depends on how many - and which - of the other portfolios are held by party colleagues. Thus, one way or another, the extent and weight of a party's presence at the cabinet table strongly influences the overall direction of government policy. ${ }^{1}$

The main empirical foray into the field of portfolio allocation is Browne and Franklin's (1973) study of portfolio allocations in Western European parliamentary governments between 1945 and 1969. It was motivated by Gamson's (1961: 376) hypothesis that: 'Any participant will expect others to demand from a coalition a share of the payoff proportional to the amount of resources which they contribute to a coalition.' Equating resources with a party's seat share, as Gamson (1961:374) appears to suggest, and payoffs with its quantitative portfolio share, Browne and Franklin (1973: 460-461) found striking support for this conjecture. Not only did the two variables correlate almost perfectly $(r=0.926)$, but the regression analysis yielded an intercept close to zero and a slope coefficient of nearly one - values indicative of a near-perfect one-to-one relationship. They also found a slight tendency for smaller parties to receive more than their proportional share and larger parties to receive less (especially in coalitions with fewer parties). ${ }^{2}$ Nevertheless, this small-party bias scarcely marred the striking proportionality that has led scholars (e.g., Morelli 1999; Fréchette et al. 2005) to dub the relationship 'Gamson's Law'.

Despite this distinction and the empirical evidence that sustains it, the proportionality finding appears to contradict the thrust of an important class of non-cooperative models of bargaining that highlights the advantages of the proposer. Examples include the bilateral bargaining model of Rubinstein (1982) and especially its extension by Baron and Ferejohn (1989) to multiparty, majority rule legislative settings (also see Harrington 1990). Indeed, 
the application of the Baron-Ferejohn model and its offshoots in areas such as distributive politics, economic policy making and inter-chamber bargaining has been so extensive that, as Fréchette et al. (2005: 1498) note, it has become 'the most frequently used formal model of legislative bargaining'. As applied to parliamentary government, the model's key implication is that the formateur, by offering coalition partners no more than their expected payoffs from not entering the coalition, will be able to reserve for his or her party a portfolio payoff that exceeds the party's proportional share of resources. The 'fairness' code that seems to be at play in Gamson's Law is thus replaced by the more hard-nosed idea that proposal power is an exploitable resource.

We therefore have an empirical relationship impressive enough to warrant the status of a scientific law (at least in the eyes of some) in apparent conflict with a class of bargaining models that includes the most prominent formal model of legislative bargaining. What makes the dilemma particularly acute is that even the very small deviation from proportionality noted above appears to run in the opposite direction to what proposer models anticipate: it is the smaller parties that are slightly favoured in terms of payoffs, even though most formateurs belong to large parties. In earlier work (Warwick \& Druckman 2001), we attempted to unravel the conundrum by adapting Laver and Hunt's (1992) survey-based rank ordering of major portfolios in order to determine whether the law holds up in 12 West European systems when portfolio saliences are taken into account. We found that the use of salienceweighted portfolio shares does not noticeably diminish or alter the proportionality effect.

Our result, however, is far from definitive. In converting a partial ordinal ranking of key portfolios for each country into a set of salience weights for all portfolios, certain leaps of faith had to be embraced. There was little choice, for instance, but to give all unranked portfolios (the majority in most governments) the same weight; in addition, the increments in salience between ranked portfolios were assumed to be equal. Perhaps most significantly, how far the prime ministership - a post almost always held by formateurs - stands above the other portfolios could only be guessed at. We showed that, assuming the other weights were accurate, the prime ministership would have to be 4.19 times as salient as the average other portfolio for a significant degree of formateur over-compensation to appear, but the plausibility of such a scenario could only be left to the reader's judgment. ${ }^{3}$

Potential inaccuracy in estimating portfolio salience is not the only source for doubt concerning our conclusions. The focus of our study was on revamping the dependent variable, but the independent variable (i.e., seat shares) can also be challenged. As Lucas (1978: 184) observed: 
It is fallacious to expect that one's voting power is directly proportional to the number of votes he can deliver. . . Power is not a trivial function of one's strength as measured by his number of votes. Simple additive or division arguments are not sufficient, but more complicated relations are necessary to understand the real division of influence.

Gamson's Law is thus vulnerable at both ends. In the next two subsections, we examine these concerns in more detail and describe how we intend to address them in the present study. We begin by considering the ways in which portfolio salience may figure in the strategic calculations of parliamentary parties and outlining how our expert surveys address the need for an appropriate and comprehensive measurement of portfolio salience. We then turn to the more theoretical issue of whether the relevant causal factor is seats or bargaining power, and the various ways in which the latter has been conceived.

\section{Payoffs: The salience or importance of portfolios}

Gamson's Law has usually been assessed on the basis of the number of portfolios allocated to each coalition member, but what about the qualitative allocation? How quality affects the picture will depend on whether parties place different valuations on the portfolios to be distributed or whether there is general agreement concerning their relative importance. If the former, determining if payoffs are proportional would require knowledge of how each party in a system rates the various portfolios - a requirement that may be impossible to meet in practice. More important, the situation would also be very demanding for the parties involved in bargaining over portfolios. For any party to assess the extent to which a given proposal favours itself relative to the other coalition parties, it would have to be able to make evaluations such as 'Party A places 40 per cent more value on the Justice Ministry than Party B places on the Education portfolio' - for all parties in the coalition and all portfolios in the government. Without this kind of knowledge, it would be possible, for example, for all members of a coalition government to believe simultaneously that they have been over-compensated in the allocation of portfolios. ${ }^{4}$

This is an unlikely state of affairs, but it is just as improbable that parties would be able to avoid it by making the kinds of inter-party comparisons of utility suggested above in an across-the-board fashion (although there may be occasional exceptions). A much more likely scenario is that bargaining over portfolios proceeds on the basis of a common, if somewhat rough, understanding of their relative prestige or importance. The prime ministership, for example, is almost certainly recognized in all countries and by all parties as the pre-eminent post, usually followed by portfolios such as Finance and Foreign 
Affairs (Browne \& Feste 1975; Bueno de Mesquita 1979; Laver \& Schofield 1990: 181). ${ }^{5}$ It is likely, however, that this understanding encompasses not just the order of importance of the various portfolios in their system, but also the magnitudes of the differences among them. It would not be enough for a party to know that the prime ministership is worth more than any other portfolio in order to determine whether the party that receives it is being overcompensated (by whatever standard is in use); it would also have to know how much more valuable the prime ministership is. In other words, if parties weight the portfolios by their respective salience values in order to determine the overall payoffs to themselves and the other parties from a given portfolio allocation, it is necessary that they utilize cardinal weights.

While the assumption that actors evaluate portfolio payoffs in terms of a shared valuation of cabinet posts greatly reduces the expectations made of them, this last consideration implies that they must still have a fairly sophisticated understanding of that evaluative scheme. For analysts, the bar must be set correspondingly high: a thorough testing of Gamson's Law will require cardinal ratings of all the portfolios that appeared in the governments of a substantial number of countries over a substantial expanse of time. This requirement, needless to say, has never been fully addressed; the closest we have come is Laver and Hunt's (1992) ordinal ranking of major portfolios in West European systems, which formed the basis for our earlier study (Warwick \& Druckman 2001). We therefore set out to remedy this 'data gap' by conducting a new expert survey of portfolio salience in each of 14 West European systems that have had at least some experience with coalition governments. ${ }^{6}$ The distinguishing feature of these surveys is that respondents were asked to provide cardinal ratings for portfolios that had appeared in the coalition governments of the postwar democratic era (until 2000) for the country in question. ${ }^{7}$ The ratings were calibrated by asking respondents to set the salience of an average portfolio in their system to a value of ' 1 ' and to select scores above or below that value so as to convey the proportional increase or decrease in salience that characterize non-average portfolios. Thus, a score of ' 1.5 ' would indicate a portfolio whose salience is 50 per cent above average; ' 0.67 ' would denote a portfolio with a salience just two-thirds that of an average portfolio. The final rating for each portfolio is simply the mean rating provided by the respondents.

The decision to seek salience estimates for portfolios in governments spanning so broad a period was motivated by the goal of undertaking a comprehensive re-testing of Gamson's Law, but it clearly entails certain risks. Perhaps the most obvious is that, in seeking a single salience estimate for each portfolio, we must assume that portfolio salience does not change over time. Fortunately, the validity of this assumption can be tested by assessing whether 
Gamson's Law appears to weaken as one goes further back into the past. Of more immediate concern is the fact that, in most countries, the list of portfolios included in the survey could not be fully comprehensive because the numbers of distinct portfolios that have appeared over the course of the observation period are simply too large. Not only do governments create and dissolve portfolios from time to time, but responsibilities are frequently reshuffled; for example, Culture may have been a separate portfolio for a while, then combined with Leisure, which was subsequently hived off and added to Sport, and so forth. Another complication is that it is not always evident how many distinct portfolios have existed in a given country in the postwar era. A portfolio that was identified in our primary source, Keesing's Contemporary Archives, as 'Education and Research' in one government, for instance, may appear as 'Education' in the next, leaving it unclear whether we are dealing with the same portfolio or an altered one.

The tactic we adopted to deal with these complexities was to identify the core units or 'posts' and to request ratings for them. Thus, if Research never appears apart from Education, we requested a single rating for the entire Education and Research portfolio (on the assumption that 'Research' is implied when the portfolio is listed simply as 'Education'). If there are any governments where Research appears on its own or attached to another portfolio, however, we would request separate ratings for the posts of Education and Research (provided the latter post was present in enough governments to warrant inclusion in the survey). ${ }^{8}$ This approach reduced the number of posts to be rated, but it entails that the salience ratings for separate posts be summed whenever the posts are combined into a single portfolio; a similar logic dictates that we split the rating equally when a portfolio is divided (and separate ratings could not be obtained for the individual posts). These procedures, too, are not without risk. The amalgamation of two portfolios may occur, for instance, because neither of them remains sufficiently important to merit separate representation at the cabinet table; if so, summing their separate ratings would overstate the importance of the combined post. More problematic is the treatment of the posts that, because they existed only briefly a long time ago, had to be omitted from the survey: they were simply assigned the average or default score of ' 1 '.

How significant are these decisions? Some idea of their potential impact can be gleaned from Table 1, which shows the extent to which these 'extensions' had to be used to achieve full coverage in each country. Full coverage for a country would consist of ratings for all portfolios in all coalition governments (apart from caretaker governments) that held office in that country for the period beginning with the first democratic government that formed after 1945 and ending in the year 2000. ${ }^{9}$ As the first column shows, we were able to obtain 
THE PORTFOLIO ALLOCATION PARADOX

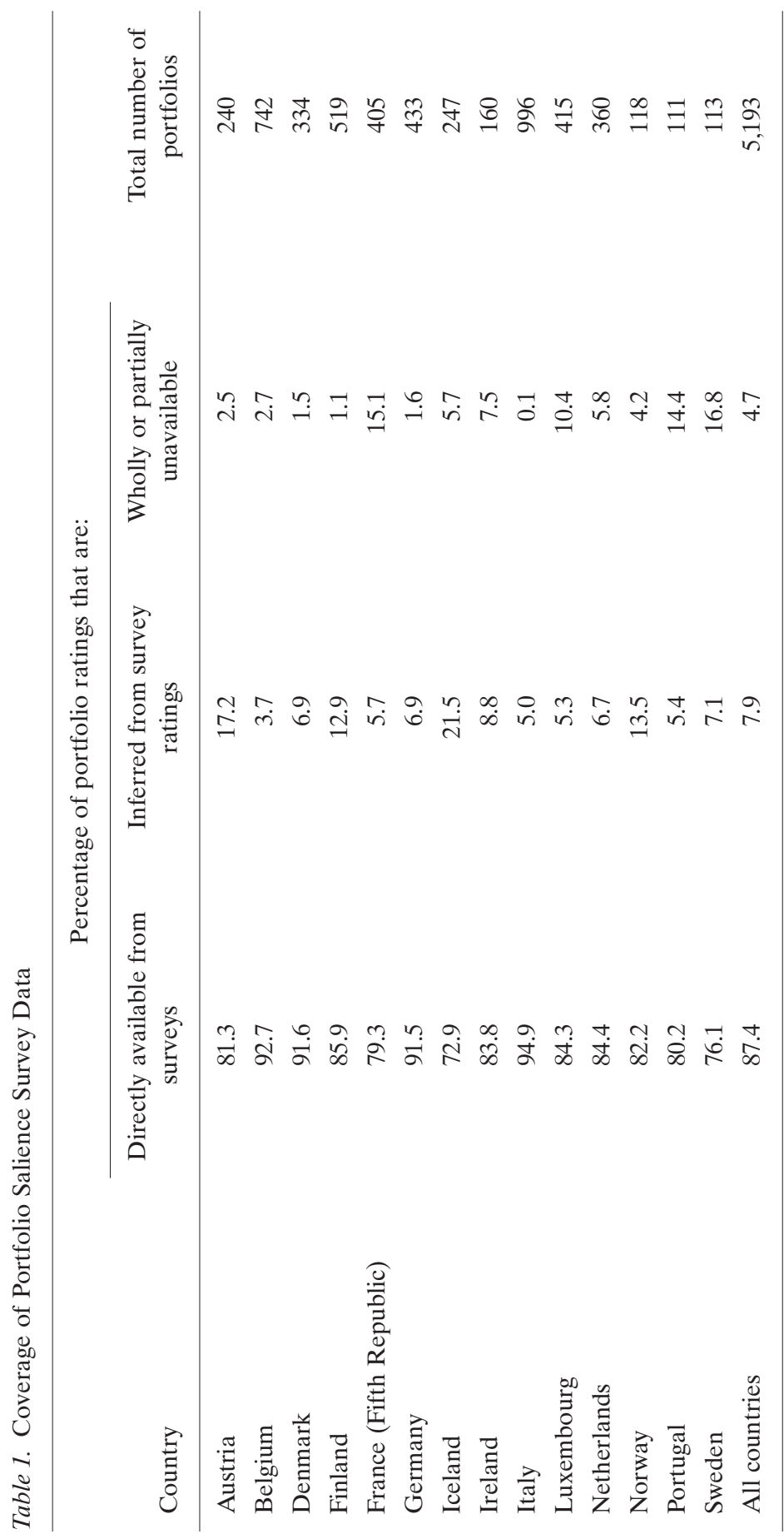


salience estimates for 87.4 per cent of the 5,193 portfolios in question without resorting to any of these stratagems. The stratagems of summing ratings, splitting ratings and so forth allowed us to infer ratings for another 7.9 per cent of portfolios. This leaves only 4.7 per cent of portfolios unrated or with unrated components (of which just 1.0 per cent were wholly unrated and therefore simply received the default score) ${ }^{10}$

The high proportion of directly estimated portfolios suggests that the potential for error in inferring ratings for the other portfolios is relatively small, but it nevertheless should not be ignored. In the analyses that follow, two versions of salience-weighted portfolio shares will therefore be examined: one based just on the portfolios for which the surveys directly provide ratings and a second that utilizes the various extensions to provide coverage for the entire set of portfolios. Before we can proceed to an examination of what these two versions of portfolio payoffs can tell us about the viability of Gamson's Law, however, we must turn to the issue of the appropriate causal concept: seat share or bargaining power.

\section{Resources: Seat share or bargaining power?}

Parties that control more resources will presumably demand and receive a greater share of (salience-weighted) portfolios, but what constitutes a party's resources? For Gamson (1961: 374-376), the critical resource is legislative seats since they determine whether a coalition is winning or not. ${ }^{11}$ Browne and Franklin (1973: 457) agree that 'the most obvious, and probably the most important, set of resources a party brings to the government is its share of parliamentary seats'. While the empirical evidence they marshalled would seem to support this interpretation, we have seen that it is nonetheless problematic. As Laver and Schofield (1990: 173) put it, 'why do parties with a lot of bargaining power not flex their muscles and demand the lion's share of cabinet portfolios, regardless of the seat distribution in the legislature?'

Measures of bargaining power have been applied to the analysis of voting in the European Union Council of Ministers, the United States Electoral College, international organizations, corporations and many other venues (see Felsenthal \& Machover 1998). These measures typically focus not on size, but on the extent to which a party is pivotal to winning coalitions (i.e., necessary to make the coalition winning). The two best-known measures drawn from cooperative game theory are the Shapley-Shubik index and the Banzhaf index (Leech 2002: 2). To see how they work, consider a three-party 100-seat legislature where Parties A and B each control 45 seats and Party C controls the remaining 10 seats. The Shapley-Shubik index is calculated by taking the full set of permutations of voting orders (i.e., $\mathrm{ABC}, \mathrm{BCA}, \mathrm{CAB}, \mathrm{CBA}, \mathrm{BAC}$ and 
$\mathrm{ACB}$ ) and determining the proportion of times each party casts the pivotal vote. Since the second vote is always pivotal in this example, each party is pivotal in a third of the permutations and would receive a score of 0.33 . The standardized Banzhaf index differs from Shapley-Shubik index in that it considers all possible winning coalitions just once and calculates the proportion in which each party is pivotal without regard to any voting order. In this example, each party is pivotal in two of the four winning coalitions $(\{\mathrm{AB}\},\{\mathrm{AC}\},\{\mathrm{BC}\}$ and $\{A B C\})$; therefore, with standardizing so that party scores sum to unity, each party would again receive a value of 0.33 . (Needless to say, the two indices do not always agree.)

A common critique levelled against measures such as these is that they assume that all coalitions are equally likely to occur (Felsenthal \& Machover 1998). ${ }^{12}$ The measurement of bargaining power used in non-cooperative game theory models such as the Baron-Ferejohn model departs from this practice by focusing instead on the number of minimal winning coalitions to which a party can belong, capturing this with what is termed a 'minimum integer representation' of the game (Ansolabehere et al. 2005: 552; Snyder et al. 2003: 5). A minimum integer representation is the smallest vector of integers that can be assigned to the parties in a legislature so as to reproduce the set of minimal winning coalitions in that legislature. In the hypothetical legislature discussed earlier, all three parties would receive integer values of ' 1 ' because these are the smallest integers that can reproduce the set of minimal winning coalitions generated by their actual seat sizes $(\{\mathrm{AB}\},\{\mathrm{AC}\}$ and $\{\mathrm{BC}\})$. There are a couple of issues to note with respect to the calculation of voting weights. A minimum integer representation of a voting game is unique whenever there are five or fewer parties because in these situations all minimal winning coalitions share the same total weight (which makes the game 'homogeneous'); in larger games, however, the integer representation may not be unique (Ansolabehere et al. 2005). ${ }^{13}$ Another issue concerns whether the integer weights should be divided by the total voting weight of all legislative parties or the total for just the parties in the governing coalition in creating a bargaining power index. Ansolabehere et al. (2005:3-4) argue that 'the theoretically appropriate independent variable that measures a party's bargaining strength is its share of the voting weight in the legislature'. This is certainly true of the Baron-Ferejohn model, but it is not the case for Morelli's demand-based model of legislative bargaining (Morelli 1999: 813).

The debate over which conceptualization of resources is relevant for coalition formation and portfolio allocation thus takes the form of a complex layering of issues: Should we use seat shares or bargaining power? If the latter, should it be a cooperative or a non-cooperative measure? If the latter, should it be measured relative to the legislature or the cabinet? Parsing these issues 
empirically will require the calculation of a wide variety of bargaining power measures for the legislatures of the 14 countries under examination. Fortunately, computer software is now available for this task. For power indices, we utilized Pajala et al.'s (2002) Powerslave program, which calculates ShapleyShubik, absolute and standardized Banzhaf, Coleman preventive power, Deegan-Packel, Holler, Zipke, Colomer and Johnston indices. To calculate minimum integer weights, we relied on Strauss et al.'s (2003) Minimum Integer Weights and Baron-Ferejohn Calculator. Since these weights may be taken as a proportion of the legislative or the coalitional total, the analyses that follow will examine both versions.

To sum up, this discussion has identified three critical issues confronting the study of portfolio payoffs. The first and least contentious issue concerns the measurement of the dependent variable. Scholars have long acknowledged variation in the worth of different portfolios (e.g., Browne \& Franklin 1973: 458), but have lacked satisfactory measurement of these variations. Second, most empirically oriented studies that have tested Gamson's conjecture follow his reasoning in measuring the independent variable, a party's resources, by its coalitional seat contribution or seat share; formal theoretical work, in contrast, posits the critical resource as being its bargaining power, although disagreement exists both within and between cooperative and non-cooperative approaches over how this should be measured. Third, researchers disagree on the relationship between portfolios and resources. The proportional relationship between resources and portfolios is one of the strongest findings in the social sciences, but the most utilized formal bargaining model, the BaronFerejohn model, contradicts the idea of proportional payoffs by predicting formateur over-compensation. ${ }^{14}$ In the next section, we address each of these issues by exploring the impact of portfolio salience, the alternative measures of resources, and ultimately the basic relationship between payoffs and resources.

\section{Data analysis}

The testing ground for these debates is a data set comprising the portfolio allocations to 807 parties that participated in 268 coalition governments in the 14 West European countries listed in Table 1. Although the period covered by these data (i.e., the postwar democratic period to 2000) is considerably larger than that available to Browne and Franklin thirty years ago, the tendency for seat shares and portfolio shares to be closely related remains just as impressive. In fact, the overall correlation between the two variables of $r=$ $0.943(p<0.001)$ actually exceeds the coefficient $(r=0.926)$ they reported (Browne \& Franklin 1973: 460). When the correlations are calculated on a 
country-by-country basis, only two countries produce coefficients below 0.800 (Iceland and Luxembourg), which suggests that the pattern has cross-national validity. ${ }^{15}$

The hypothesis as it was originally formulated stipulates not just that seat shares and portfolio shares are closely related, but that they are related in a one-to-one fashion. As noted earlier, Browne and Franklin (1973: 460) found that this was not quite the case: there appeared to be a bias in favour of smaller parties that induced the intercept to exceed, and the slope to undershoot, its expectation. ${ }^{16}$ This turns out to be true of the present data as well. As the first model of Table 2 shows, both the intercept $(\alpha=0.069, S . E .=0.004)$ and the slope $(\beta=0.793$, S.E. $=0.012)$ deviate significantly from their hypothesized values. The scatterplot of the relationship, shown in Figure 1, reveals the bias clearly: smaller parties tend to lie above the $45^{\circ}$ line that indicates one-to-one proportionality, while larger parties tend to lie below it. Whether these findings are theoretically meaningful depends, to be sure, on whether the dependent variable is adequately measured as well as on whether the independent variable is the appropriate one - both of which may be challenged, as we have seen. We begin the evaluation of these challenges with the dependent variable.

\section{Gamson's law and salience-weighted portfolio shares}

There is no dispute that portfolio payoffs ought to take into consideration the varying levels of importance of the portfolios, rather than just their numbers; the obstacle heretofore has been one of measurement. The potential gain lies not just in accuracy. In earlier work, we found that the apparent bias in favour of small parties could be an artefact of the failure to take portfolio salience into account (Warwick \& Druckman 2001: 638-641). Specifically, we demonstrated that the 'lumpiness' of portfolio allocations - the fact that portfolios are always allocated in their entirety to single parties - itself produces the phenomenon, particularly in the presence of random error in the allocation process. With the application of salience weightings, however, this lumpiness is smoothed out and a truer assessment of the nature of the underlying relationship becomes obtainable. ${ }^{17}$

As mentioned, two versions of a party's weighted portfolio share will be tested, one using just the portfolios (87.4 per cent of the total) directly covered in the surveys and a second utilizing the various extensions described earlier to produce saliences for all portfolios held in the various governments. In each version, a party's portfolio share is calculated as the weighted sum of portfolios allocated to it as a proportion of the weighted sum of portfolios allocated to all parties in that government, with the mean salience scores for the portfolios 


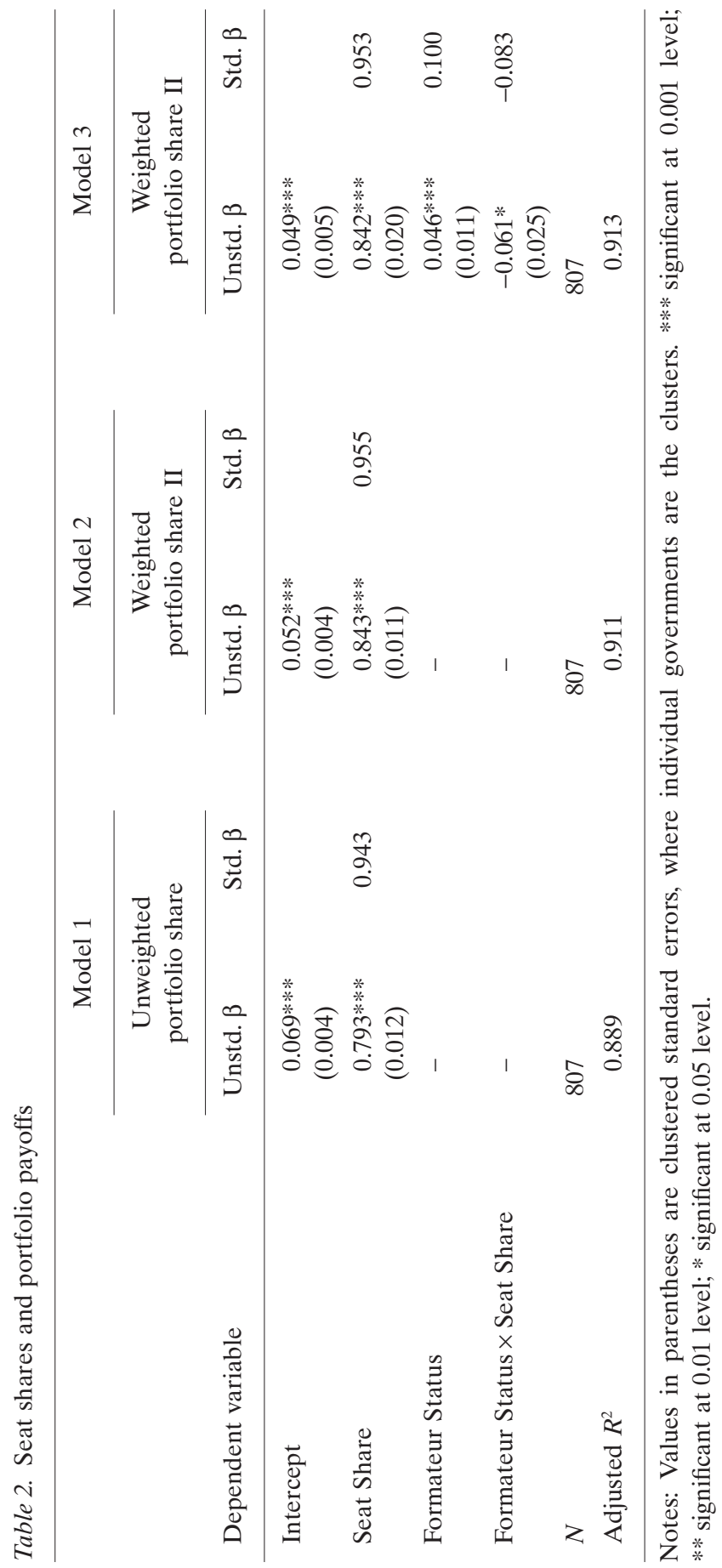


constituting the weights. The two versions will be referred to as 'Weighted Portfolio Share I' and 'Weighted Portfolio Share II', respectively.

There clearly is ample scope for errors to infect these variables: the mean estimates of the saliences of the various portfolios in each country may be inaccurate; the assumption that saliences remain constant across the observation period (which covers as much as half a century) may be unwarranted; and the need to exclude, or make additional assumptions for, some 12.6 per cent of portfolios may lead to distortions. With so much scope for error, it is more than a little surprising that the weighted portfolio shares that parties receive should turn out to be remarkably closely connected to their unweighted shares: the correlation coefficients are $r=0.971$ (Weighted Portfolio Share I) and $r=0.986$ (Weighted Portfolio Share II). Both coefficients, needless to say, are highly significant $(p<0.001)$. An obvious explanation for such high correlations is that they are the result of a strong tendency for portfolios to be given similar salience scores, thereby producing weighted payoffs that closely mirror the unweighted ones. Further examination does not sustain this interpretation, however. In the average system, the top portfolio (the prime ministership) rated by our respondents is 2.23 times as salient as the average portfolio and 4.77 times as salient as the bottom portfolio; the standard deviation across the ratings averages 0.39 units. ${ }^{18}$ Moreover, adding the various extensions to produce ratings for all portfolios causes these figures to increase substantially.

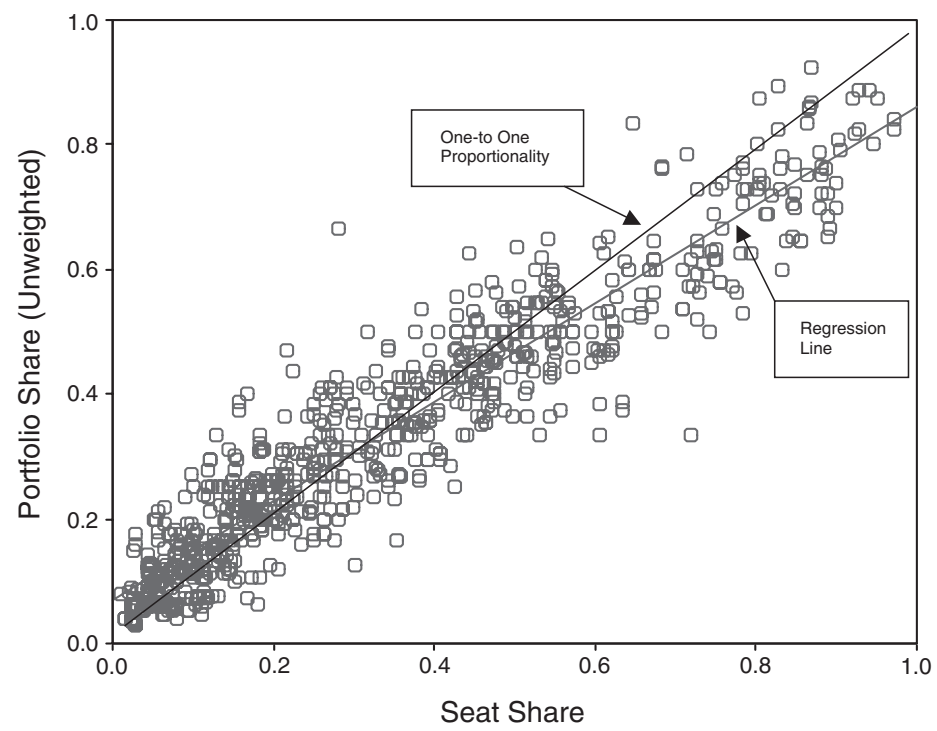

Figure 1. Testing Gamson's Law as originally specified. 
Thus, the extremely close match between the qualitative and quantitative allocations of portfolios occurs despite the existence of substantial variation in the estimated importance of portfolios.

This is an extraordinary result, suggesting that the portfolio allocation in coalition cabinets is finely calibrated to offset the very considerable differences in salience among portfolios. Moreover, it bears two further implications: that weighted portfolio shares are likely to match seat shares very closely and that the parties of formateurs, or 'formateur parties' as we shall term them, may not be compensated disproportionately in this regard, despite almost always receiving the prime ministership. The first implication is borne out in the degree of association between seat contributions and weighted portfolio shares. The correlation of seat share with the first version of weighted portfolio share, which covers only the portfolios for which the surveys directly provided weights, is identical to its correlation with the unweighted portfolio share $(r=0.943, p<0.001)$. When the comprehensive version of weighted portfolio share is used, the correlation actually rises to $r=0.955(p<0.001)$. These results indicate that none of the possible sources of error listed above has assumed serious proportions; such strong relationships could only have been generated if the expert assessments of salience, and the extensions we applied to them, are reasonably accurate for the entire observation period. ${ }^{19}$ Because Weighted Portfolio Share II provides comprehensive coverage without any apparent cost in terms of accuracy, the analyses that follow will utilize it as the dependent variable. All findings, however, would be essentially unchanged if the other version were used.

In substantive terms, the picture these correlations portray is equally clear: the introduction of the importance or salience of portfolios, far from undermining the close connection of seats to payoffs, has preserved and possibly even strengthened it slightly. This means that, contrary to what might be supposed, there is no tendency for larger and presumably more influential parties to monopolize the high-profile posts. Indeed, as before, it is the smaller parties that do especially well. The persistence of a small-party bias can be seen clearly in the scatterplot shown in Figure 2. It is also evident in Model 2, which re-calculates the regression with Weighted Portfolio Share II as the dependent variable. If the small-party bias were an artefact of the inherent lumpiness of the original dependent variable, one would expect that the use of weighted portfolio shares would eliminate it. Although the intercept and slope move closer to their theoretically expected values of zero and one, however, they still fall significantly wide of those marks. Apparently, the small-party bias in Model 1 is only partly artefactual.

We have yet to consider the role of formateur status, however. Since the relationship between seat shares and portfolio payoffs may be different for 
formateur parties, the impact of formateur status must be estimated with both a formateur status dummy variable and the interaction of that dummy with seat shares. The results are reported in Model 3. The significant positive coefficient estimated for formateur status itself, together with the significant negative coefficient estimated for the interaction term, indicate that formateur parties may receive more compensation than other parties - but only when their seat share is relatively small. In fact, the changeover from overcompensation to under-compensation occurs at a seat share of 43.6 per cent. Since most formateur parties contribute more than this percentage of their coalition's legislative weight (see Figure 2), the overall consequence is formateur under-compensation. Specifically, in the average formation, the formateur party provides 58.5 per cent of the government's total legislative weight, but receives just 55.3 per cent of the salience-weighted portfolio payoff; the average non-formateur party, in contrast, provides 21.2 per cent of the cabinet's seat share and receives 22.8 per cent of its weighted payoff. These results are very close to proportionality, but the discrepancy favours the nonformateur parties.

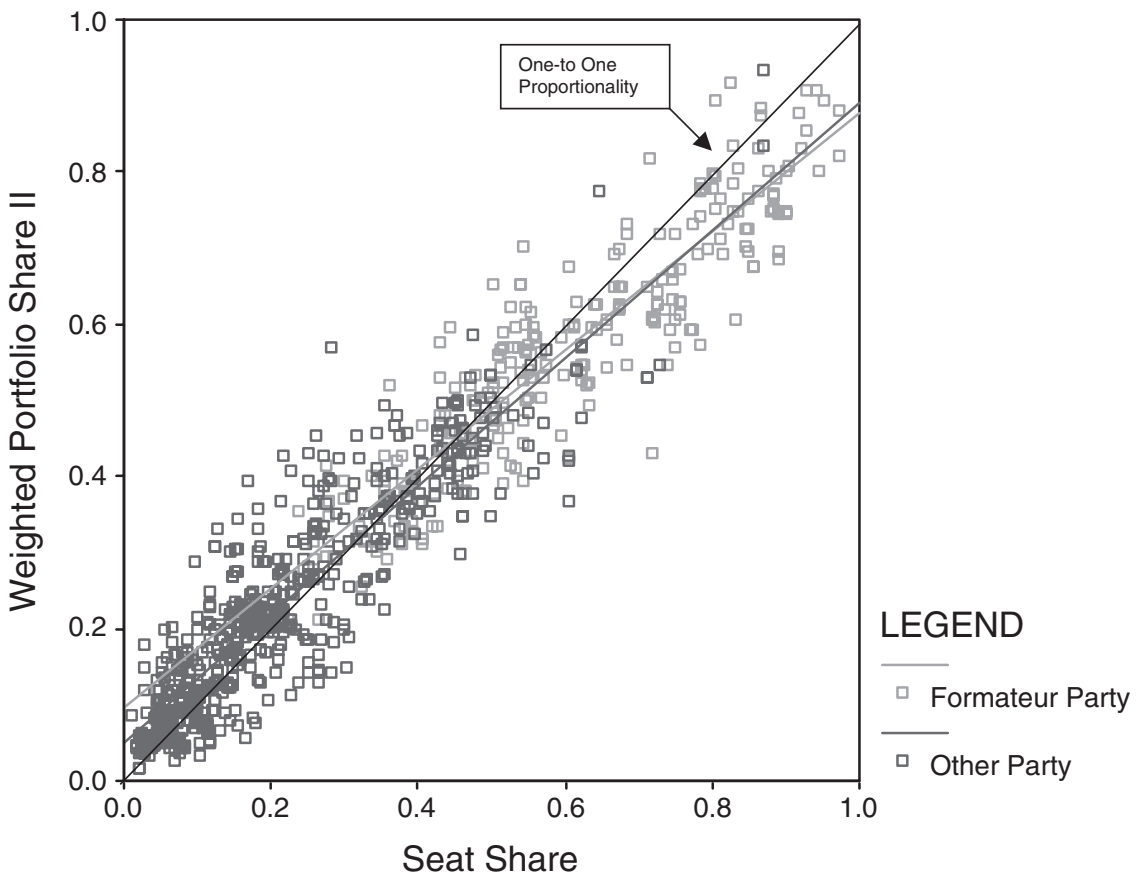

Figure 2. Gamson's Law using salience-weighted portfolio shares. 


\section{Voting weights and salience-weighted portfolio shares}

The riddle posed by the absence of a formateur advantage in the standard operationalization of Gamson's Law is thus not resolved by taking portfolio salience into account. Before we can conclude that the assumptions that underlie proposer models of bargaining are inappropriate for the process of coalition government formation, however, we must consider the other option: that the independent variable is mis-specified. This argument has been advanced vigorously in a recent pair of papers by Ansolabehere et al. (2005) and Snyder et al. (2003). Because the measure of bargaining strength they favour is the party's share of the total voting weight in the legislature, which conveys the resources that actors bring to the table in non-cooperative bargaining models such as the ubiquitous Baron-Ferejohn model, we shall begin the evaluation of the bargaining strength approach with this variable.

The way in which voting weights, so derived, relate to seat shares is shown in the scatterplot in Figure $3 .^{20}$ While voting weight does increase with seat shares, it is evident that the connection between the two is less than perfect. Particularly noteworthy are the horizontal lines of points, which represent parties in situations where voting weights are equal regardless of seat shares. The line that occurs at a voting weight of 0.33 , for example, derives from legislatures where three parties have equal bargaining power because they all are pivotal for the same number of minimal winning coalitions.

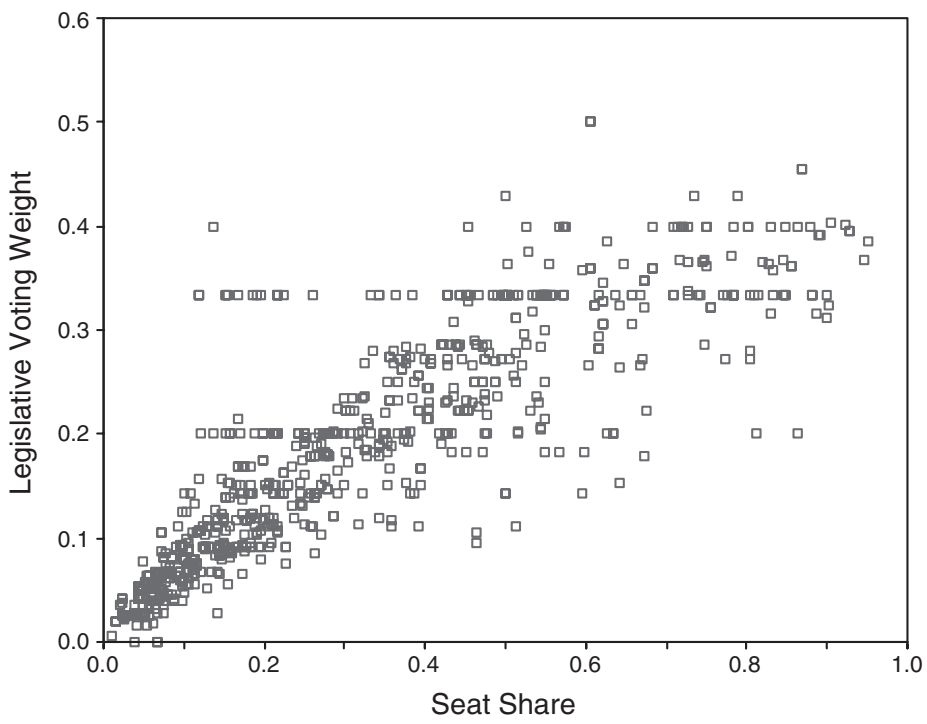

Figure 3. Seat shares and voting weights. 
The first model of Table 3 reports the results of regressing Weighted Portfolio Shares II on these voting weights. ${ }^{21}$ They clearly show that a strong relationship exists between the two. The critical issue, however, is whether the use of voting weights to measure resources allows a formateur advantage effect to emerge; only then would we be in a position to conclude that proposer models, and the concept of bargaining strength they utilize, have some empirical justification. Ansolabehere et al. (2005) and Snyder et al. (2003) support their case by demonstrating that a significant net effect is exercised on the quantitative allocation of portfolio shares by the formateur status dummy. They also show that this effect strengthens when the prime ministership is arbitrarily accorded the salience weight of ' 3 '. Indeed, they find that the use of this weighting results in an estimated coefficient for voting weight (0.98) that is statistically indistinguishable from its theoretically predicted value of one (Ansolabehere et al. 2005: 557). ${ }^{22}$ Yet can these conclusions be sustained when a better-grounded and more comprehensive measure of salience-weighted portfolio shares is used?

This issue is addressed in the second model in Table 3. It shows that the formateur dummy does convey a significant and relatively sizeable positive effect, indicating that formateur parties receive considerably more than their voting weight alone would mandate. This would seem to provide clear evidence of a formateur advantage effect, but there are several reasons for caution. First, as Ansolabehere et al. (2005: 559) themselves found, not only is the intercept significantly different from its theoretically expected value of zero (even though lumpiness in portfolio allocations is no longer an issue), but the coefficients for the two independent variables are well off their predicted values as well. ${ }^{23}$ Second, the use of a full set of salience weights does not confirm their finding (based on weighting just the prime ministership) that the voting weight effect approximates its predicted value of one. Finally, and most importantly for present purposes, the test does not take into account the tendency for formateur parties to be large. What we really need to determine is whether the higher payoffs that formateur parties receive are the result of bargaining advantages they may enjoy - or simply their greater sizes.

Model 3 addresses this issue by adding seat share to the specification. This crucial test was not undertaken by Ansolabehere et al. (2005: 558), apparently because of the risk of multicollinearity. While the multiple correlation between seat share and the other two variables is indeed high $(r=0.89)$, this statistic in itself is not a sure indicator of an estimation problem. The small standard errors reported in Model 3 indicate that there is no excessive difficulty in estimating separate effects for each of these variables, a conclusion that is supported by more formal testing. ${ }^{24}$ Substantively speaking, those effects make it very clear that seat share is by far the strongest determinant of portfolio 


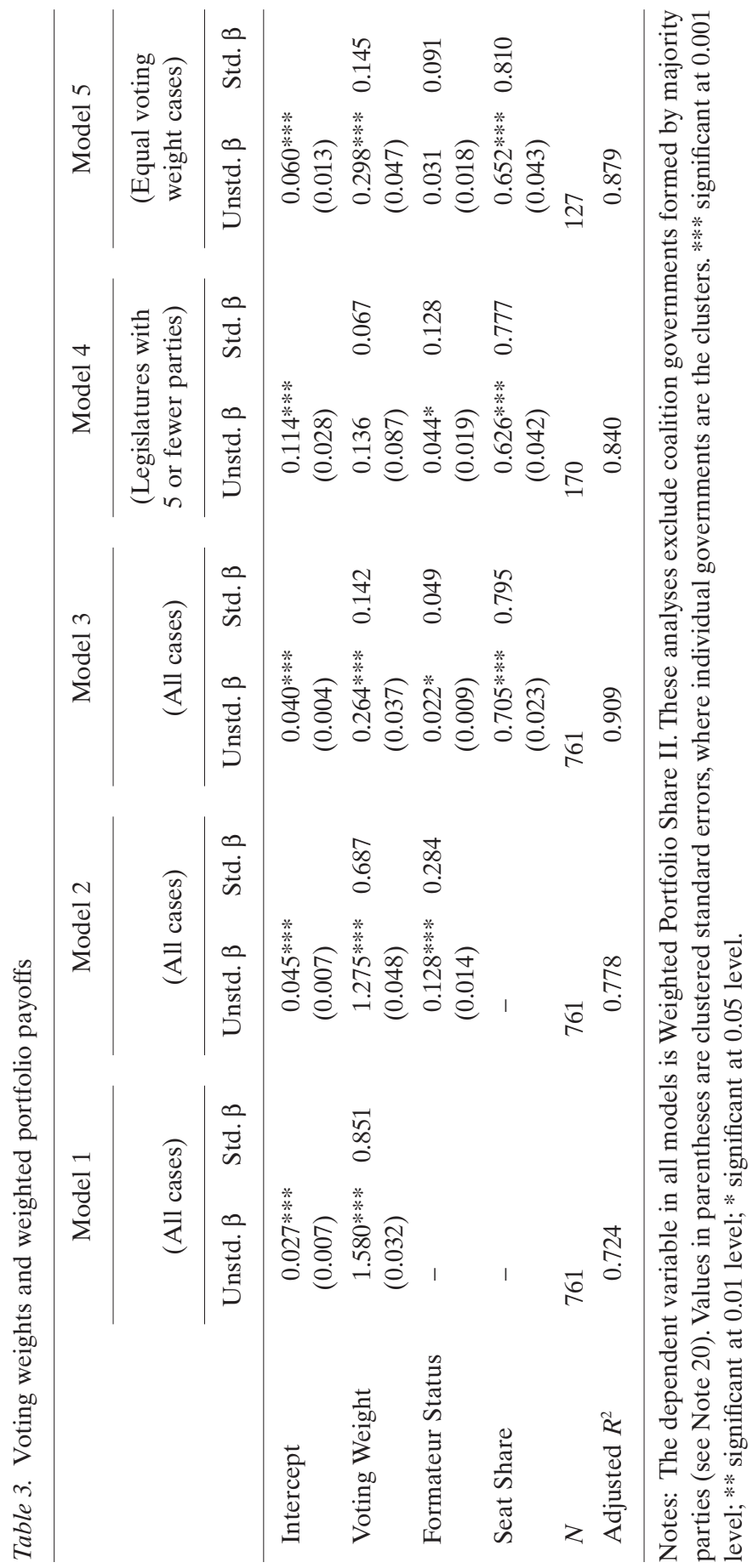


allocations. The formateur advantage, in contrast, has diminished noticeably and is now a very marginal consideration. ${ }^{25}$ In other words, the larger portfolio payoff that formateur parties appear to receive in Model 2 can be explained in large measure by their larger sizes; there is no indication that formateur status itself has benefited these parties in any great measure.

Fréchette et al. (2005: 1510-1511) suggest that formateur parties do not appear to be advantaged in previous tests of Gamson's Law because they are usually large, and because voting weights tend to be very similar to seat shares in legislatures with larger numbers of parties, thereby confounding the two effects. The first point is a valid interpretation of the results so far: formateurs are over-compensated relative to voting weight, but not relative to seat share, because they tend to be large parties whose seat contributions outpace their voting weights. Yet this does not necessarily mean that those tests of Gamson's Law are mis-specified; on the contrary, the extremely close correspondence of portfolio payoff with seat share - a connection much stronger than that produced by voting weight and formateur status in Model 2 (seat share alone accounts for 91.1 per cent of the variance in weighted portfolio share) suggests that the main guiding principle in portfolio allocations is very probably size, not bargaining and agenda-setting power. Without some convincing explanation for why the allegedly mis-specified relationship works so much better than the specification they favour, there is little option but to conclude that the allegation is not warranted.

There is, moreover, other evidence that can be brought to bear on this issue. Fréchette et al.'s second point implies that the way to differentiate these explanations is to focus on cases where voting weights differ substantially from seat shares. For instance, in legislatures of five or less parties, voting weights and seat shares are only moderately correlated $(r=0.526)$; if their explanation is correct, then the effect of seat shares should retreat, and the voting weight effect come to the fore, in these cases. In fact, the effect of voting weight weakens substantially and becomes statistically insignificant when the analysis is confined to these legislatures, as shown in Model 4.

The role of seat share can be brought into even sharper relief if we focus our examination on governments that were formed of parties with equal voting weights. These are the governments where seat shares and voting weights are totally dissociated; their member parties populate the horizontal lines in Figure 3. In these cases, payoffs should be equal for all member parties except for the formateur party, which should be advantaged; seat shares, in contrast, should play no role at all. As Model 5 shows, however, precisely the opposite occurs in these cases: portfolio payoffs are related very strongly to seat shares and only marginally (and insignificantly) to formateur status. $^{26}$ 
Another consideration that may account for the failure of the votingweight approach is the possible presence of anti-system parties. Anti-system parties are parties that, because of the unacceptability of certain of their positions or associations, are not considered suitable coalition partners; examples include the various communist parties (before 1990) as well as extreme-right parties such as the Italian MSI. As Snyder et al. (2003: 22) note, the effective bargaining environment may exclude any such parties. To assess whether this consideration affects the results, we developed a coding of antisystem parties based on Powell's (1982: 233-234) definition and identified all legislatures in which anti-system parties held 5 per cent or more of legislative seats. These are the legislatures where the anti-system presence may reasonably be deemed to have reached appreciable levels. If the analyses reported in Models 3 to 5 are confined to legislatures that lack this degree of anti-system presence, however, the results are scarcely altered. ${ }^{27}$

Thus, none of the bases proposed for interpreting Gamson's Law as spurious find support in this analysis. It is true that the concept of voting weight has much greater theoretical elaboration behind it, and it is also true that voting weight and formateur status are closely related to seat share. These points naturally suggest that Gamson's Law may be a spurious consequence of this connection, but the connection is not so close as to make it impossible to separate the effects of these variables. Moreover, there are situations, such as smaller legislatures and legislatures in which voting weight is equally distributed, where the variables diverge much more clearly. In these situations as in the full sample, the evidence points to a predominant role for seat shares. Nor can differences in measurement accuracy be blamed. Since voting weights are derived solely from seat shares, the only situation where it is possible that the two variables are not measured with equal accuracy is when voting weights are non-unique. Yet the pattern persists in legislatures of five or fewer parties, which are homogeneous and therefore have unique voting weights. Finally, it appears that the results are not distorted by a mischaracterization of the bargaining system through a failure to exclude non-coalitionable parties.

Although the seat share effect appears to be genuine, this does not mean that bargaining power is irrelevant: Model 3 does show a significant, if relatively weak, net effect for voting weight. The same basic pattern emerges if the parties' voting weights are calculated on the basis of their share of the cabinet's total weight, as specified in Morelli's model. The pattern also holds up when the various power indices are used: in all but one case (the Colomer index), the index contributes a significant net effect. Thus, regardless of which measure is utilized, some residual influence appears to emanate from bargaining strength. Given the preponderant influence of seat share, there is scant justification for concluding that bargaining power is the fundamental causal factor, but these 
various measures of bargaining power are clearly capturing some explanatory power that seat share alone does not. Further examination reveals that this extra component relates, at least in part, to the small-party bias noted earlier in the analysis and first identified by Browne and Franklin (1973). A characteristic of all the measures of bargaining power used here is that smaller parties are relatively advantaged. This can be shown by taking the bargaining differential - that is, difference between a party's bargaining power and its seat share - and correlating it with seat share; a negative correlation would indicate that smaller parties tend to be more favoured in terms of bargaining power. All measures of bargaining power produce this effect at a significant level; with legislative voting weights, for instance, the correlation is a striking $r=-0.923$ $(p<0.001)$.

Since smaller parties are also advantaged in terms of portfolio payoffs, it seems likely that the two advantages are related. This possibility can be assessed by relating the bargaining differential of parties to their portfolio differential (i.e., the difference between portfolio share II and seat share). The scatterplot of this relationship is shown in Figure 4. It is evident that there is a substantial tendency for parties that have more bargaining power than their

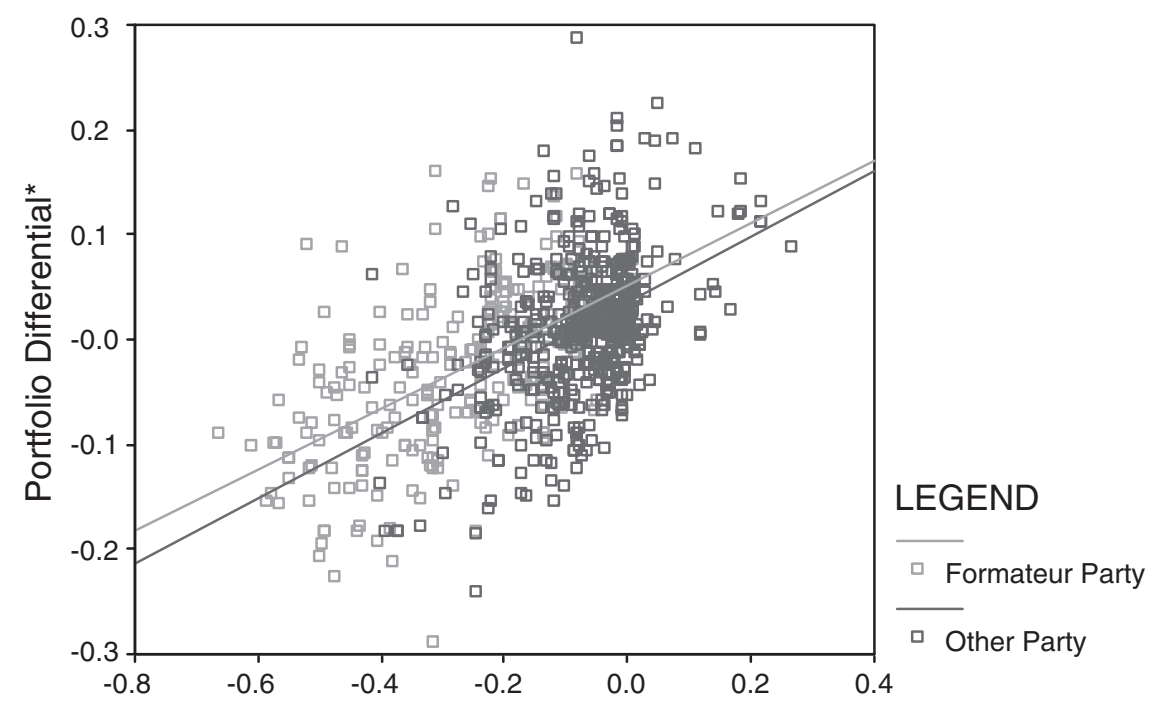

Bargaining Differential ${ }^{* *}$

${ }^{*}$ Portfolio Differential $=$ Weighted Portfolio Share - Seat Share

**Bargaining Differential $=$ Voting Weight - Seat Share

Figure 4. Bargaining differential and portfolio differential. 
size would indicate to receive over-sized portfolio shares. ${ }^{28}$ It is also evident that formateur parties are disadvantaged in this respect since their large size generally means that they are under-endowed in terms of bargaining power (note their concentration on the left side of the scatterplot). The fact that the regression line for formateurs lies above that for other parties indicates that formateur status helps to offset this disadvantage, but only to a small extent. The overall result is that formateurs are still under-compensated relative to their size, as we have seen.

While bargaining power appears to play a role in portfolio payoffs, it is important to keep that role in perspective. On average, the predicted payoff based on regressing Weighted Portfolio Share II on seat share alone deviates from the actual payoff by 5.54 per cent. If we add legislative voting weights to the model, the gap between predicted and actual payoffs falls to 5.39 per cent - a very marginal improvement indeed. Although smaller parties may occasionally be able to improve their payoff if they find themselves in situations where their bargaining power outpaces their legislative size, the effects are microscopic at best. Overall, seat-payoff proportionality dominates to an impressive degree.

\section{Concluding remarks}

The allocation of portfolios constitutes a key outcome of the government formation process, bearing major implications for public policy and perhaps ultimately affecting the electoral fate of parties (Narud \& Valen 2001). Despite its importance, relatively little attention has been devoted to this aspect of coalition governance - especially when compared to work on coalition formation and duration. This lack of attention undoubtedly derives from the unparalleled support that Browne and Franklin (1973) found for the relationship now known as Gamson's Law. This study was motivated by a desire to determine whether the relationship merits the lofty status bestowed upon it.

This may seem an unusual objective in view of the strength of the evidence, but in this case the law's credibility is undermined by doubts implicating both its dependent and independent variables. To address the former doubt, we conducted expert surveys of portfolio salience in 14 West European countries in order to derive cardinal estimates of the salience-weighted payoffs to coalition parties in these countries in democratic governments spanning the postwar period. To address the latter, we calculated a variety of bargaining power measures, including most notably the measure that underpins a stream of non-cooperative legislative bargaining models whose prime implication contradicts the law's foundation: the principle of proportional payoffs. 
Naturally, the means we have adopted to address these doubts may raise doubts, or at least questions, of their own. Is it appropriate to apply salience estimates collected in 2000-2001 to governments ranging back to the 1940s, for instance, and should we make inferences about portfolios that were not included in the surveys or simply calculate payoffs without these portfolios? Which of the many different bargaining power indices should we use, or should it be captured by the concept of voting weights characteristic of noncooperative models? If the latter, does it matter that larger legislatures may not have a unique set of voting weights, or that formal modellers disagree over whether they should be calculated relative to the cabinet or relative to the whole legislature? As it happens, none of these issues confounds our results in a significant way. The evidence suggests that the salience estimates produced by our surveys can be applied to the entire data set without a noticeable weakening of results and that the extensions we adopted to achieve total coverage of portfolios are fully warranted. As for bargaining strength, it does not seem to matter which measure is used, nor, for voting weights, whether the legislatures are homogeneous (in the formal modelling sense) or not. In large measure, these conclusions hold because the results are so clear and strong: cabinet portfolios, in both number and value, are allocated in very close proportion to the seat contributions of cabinet parties, and the bargaining strengths of these parties distort this allocation principle only very slightly (or very occasionally).

That Gamson's Law should survive these doubts and challenges as well as it does is surprising in some respects. For instance, while approximate quantitative proportionality is easy to achieve, the ability of coalescing parties to calibrate the qualitative or salience-weighted allocation so finely is truly remarkable. That they should even attempt to do so is also remarkable. It is surely a highly plausible assumption that formateurs will do considerably better for themselves, especially as they can generally lay claim to the prime ministership. Yet the power that ought to come with formateur status appears to yield little in terms of portfolios; to the extent that proportionality is systematically violated, the benefit accrues not to formateur parties, but to some of the smaller parties with which they negotiate. All that formateur parties appear to be able to achieve is to moderate the ability of small parties to exploit their bargaining advantages. This 'field' result, moreover, is corroborated in large measure by laboratory experiments, which have consistently found that proposers do not exploit their power to the degree predicted by the Baron-Ferejohn model (e.g., Fréchette et al. 2003). ${ }^{29}$

Why do proposer models fail to characterize correctly the allocation of portfolios in coalition governments? Typically, models fail reality because they abstract away essential contextual features. Among the more obvious 
simplifications of proposer models, for example, is that they ignore historical relationships among parties or the possibility that parties anticipate the effects of current bargaining on future bargaining situations or on their electoral fortunes. ${ }^{30}$ In other words, it could be that parties do not exploit their agendasetting power in any one situation because they are involved in longer-term relationships and find it more advantageous, in terms of portfolio benefits and/or their ability to justify outcomes to the electorate, to resolve differences on the basis of a norm of parity or fair shares.

While proposer models are clearly challenged by our results, it is important to realize that the challenge extends far beyond that class of formal model. Morelli's (1999) model, for example, eliminates the formateur advantage prediction by replacing the Baron and Ferejohn's assumption that the proposer can make a take-it-or-leave-it proposal with the stipulation that the formateur simply chooses the order in which different parties can make portfolio demands. Nevertheless, the model still predicts that payoffs will be proportional to bargaining power. On its face, this, too, seems a sensible intuition why should a smaller party that is pivotal to a host of coalitions not demand more than a larger party that lacks this degree of leverage? Our analyses have shown, however, that bargaining power as measured by a wide variety of indices affects things only at the margin. Since many game theoretic approaches to bargaining share the basic principle that payoffs should reflect bargaining power, they all are brought into question by this finding. ${ }^{31}$ As these remarks suggest, our results - while very clear in themselves - have reinforced rather than resolved a fundamental tension between theory and empirical work. Although it has been observed that coalition research is exemplary in its merging of theory and data (e.g., Laver 1998), we have found that the evidence sustains neither the most popular theory of legislative bargaining nor widely applied measures of bargaining power. What remains is an empirical relationship still deserving of its law-like status - but in acute need of a firm theoretical foundation.

\section{Notes}

1. The principal exception to the idea that ministers need to accommodate coalition partners is found in Laver and Shepsle's (1996) portfolio allocation model of parliamentary governance, which is predicated on the assumption that individual cabinet ministers have total control of policy making in their jurisdictions. Even here, however, the more cabinet portfolios a party has, the more government policy will accord with its own policy preferences.

2. Browne and Franklin (1973) call it the 'relative weakness effect'; to enhance clarity, we shall use the term 'small-party bias' (see also Browne \& Frendreis 1980). 
3. The uncertainty over the salience of the prime ministership also meant that we could not determine if the small-party bias is still present when weighted portfolio shares are used.

4. This would happen, e.g., if each party gets its proportional share in quantitative terms and that share consists of portfolios that have, overall, above-average value to it. This would be true regardless of whether over-compensation is defined in terms of seat shares or bargaining power.

5. This does not rule out the existence of party-specific preferences over portfolios, which Budge and Keman (1990) have demonstrated. While a conservative party may place less importance on holding the labour portfolio than a socialist party does, e.g., the assumption is that both parties share a sense of the approximate value of the portfolio and use that value in calculating overall portfolio shares. This is equivalent to an individual inheriting, say, a valuable automobile that he happens not to like: when he offers it for sale or trade, he will still expect to receive its full market value.

6. The countries are listed in Table 1. Potential respondents were identified from the list of respondents to Huber and Inglehart's (1995) expert survey of party positions, the membership list of the European Consortium for Political Research, literature searches and through referrals by respondents. The responses are distributed so as to provide at least ten respondents for each country except Luxembourg, which was not included in the Huber and Inglehart survey and for which it proved very difficult to identify potential respondents. Further details on the survey are reported in Druckman and Warwick (2005), which also contains a complete listing of the portfolio saliences used in this investigation.

7. The list of portfolios to be rated derives primarily from an examination of the portfolio composition of each of these governments, as listed in Keesing's Contemporary Archives (1945-2000). Additional information for more recent years was provided by the data yearbooks of the European Journal of Political Research and, especially for France, by Müller and Strøm (2000).

8. Other tactics utilized to cope with the complexity of portfolio listings include using a generic rating for 'ministers without portfolio' to handle the enormous number of such positions (each with different areas of responsibility) in Italy. These are discussed in more detail in Druckman and Warwick (2005).

9. Caretaker governments are excluded because the expectation that they will occupy power in a non-partisan manner renders the value of portfolios unclear. It turns out that this exclusion does not affect any of the results noticeably. Portfolios held by nonpartisan figures are also excluded from the calculations in order to keep the focus on party resources and payoffs.

10. Another reason for confidence in the portfolio ratings is that various tests, including Cronbach's alpha for inter-respondent agreement, established that they are highly reliable. These tests are reported in Druckman and Warwick (2005).

11. Gamson (1961: 381-382) explicitly addresses the use of alternative resource measures, specifically the Shapley-Shubik power index. His questioning of the idea that portfolio payoffs should accord with index scores makes it clear that he views resources as votes or seats (see also Fréchette et al. 2005: 1499).

12. Minority governments disappear from the calculations since they have no pivotal parties, but this may not be the case for surplus majority or oversized coalitions. E.g., if parties A, B and C controlled 50 seats, 49 seats and 1 seat, respectively, party A would be pivotal for coalition $\{\mathrm{A}, \mathrm{B}, \mathrm{C}\}$ even though that coalition is not minimal winning. 
13. For computational and other details concerning voting weights, see also Morelli (1999: 813), Snyder et al. (2003) and Fréchette et al. (2005).

14. To see some of these differences, recall the earlier three-party legislature example. In this case, both the Baron-Ferejohn model and Morelli's model predict the formation of a minimal winning coalition consisting of either $\mathrm{A}$ or $\mathrm{B}$ with $\mathrm{C}$. Assume $\mathrm{A}$ and $\mathrm{C}$ form that coalition, with A acting as the formateur. In this case, Gamson predicts that party A would receive 81.8 per cent (45/55) of the portfolio payoff and party $\mathrm{C}$ would receive the remaining 18.2 per cent (i.e., proportional to seat shares). Baron and Ferejohn predict that party $A$ would receive $1 / 3+1 / 3=2 / 3$ and party $C$ would receive $1 / 3$ (i.e., the non-formateur receives a share proportional to its bargaining power in parliament and the formateur receives the same plus the bonus equal to party B's unclaimed bargaining power). The Morelli model, which is not a proposer model, predicts that $\mathrm{A}$ and $\mathrm{C}$ would each receive half the portfolios (proportional to relative bargaining power, which is equal in this case).

15. The correlations are $r=0.700$ for Iceland and $r=0.788$ for Luxembourg. One possible reason for these lower values is that these countries tend to have small cabinets, which makes proportionality more difficult to achieve.

16. In fact, they reported the reverse, but this is because they regressed seat shares on portfolio shares. With portfolio shares as the dependent variable, their slope estimate would be 0.799 , virtually identical to our finding.

17. We also demonstrated that this type of artefact can be eliminated by forcing the regression through the origin (Warwick \& Druckman 2001:641-642). This corrective step is not needed here, but there may be another reason for removing the intercept. Snedecor and Cochran (1989: 174) note that in situations where 'the nature of the variables $\mathrm{Y}$ and $\mathrm{X}$ makes it clear that when $\mathrm{X}=0, \mathrm{Y}$ must be zero', the regression should be run through the origin (see also Rawlings et al. 1998: 21). Although it is technically possible for parties without parliamentary representation to receive cabinet posts, none do in the present data set and, given the dependence of cabinets on parliamentary support, it seems highly unlikely that it would ever happen. Hence, a case can be made that the realities of parliamentary governance impose a zero intercept. It turns out, however, that none of our conclusions is substantially altered if an intercept is excluded from estimations of Gamson's Law.

18. The tendencies are similar in all systems. In fact, the smallest ratio of highest to lowest saliences (for Norway) is 3.22 and the smallest standard deviation (for Belgium) is 0.312.

19. The over-time relevance of the weights is also indicated by the fact that these coefficients decline only slightly, to $r=0.940$ and $r=0.951(n=348)$, respectively, when the analysis is confined to governments formed before 1970.

20. Ansolabehere et al. (2005: 556) exclude coalition governments formed by majority parties, observing that, apart from a few Australian cases, they were formed immediately after the Second World War in defeated countries (and presumably reflect special circumstances). The present data do not cover Australia, but do cover the French Fifth Republic, which includes five such governments. Like the Australian cases, these cases cannot be attributed to special circumstances (they did not occur at the beginning of that regime, which might be interpreted as a crisis period). Nevertheless, we shall follow their example of excluding all such cases. It should be noted, however, that such cases clearly violate the proposition that voting weights determine portfolio shares, which means that this exclusion biases the test in favour of their explanation. 
21. Since it is possible for a party to have parliamentary seats but no voting weight - such parties are often referred to as 'dummy' parties - the appropriate specification must include an intercept term. In fact, there are 32 cases of dummy parties appearing in cabinets, in clear violation of the hypothesis.

22. Snyder et al. (2003: 20) find that the formateur advantage also strengthens when the weighting scheme is supplemented by according the finance and foreign ministerships arbitrary weights of ' 2 '.

23. The expectation is that $\beta_{1} \approx 1-\beta_{2} / 2$, where $\beta_{1}$ is the coefficient for formateur status and $\beta_{2}$ is the coefficient for voting weights (Ansolabehere et al. 2005: 554). In Model 2, the left-hand side of this equation equals 0.128 and the right-hand side equals 0.363 .

24. The variance inflation factors (VIFs) average 3.50 for the three independent variables (the maximum is 4.82). VIFs above ten are normally considered indicative of a multicollinearity problem (Kennedy 1998: 190).

25. If an interaction term between formateur status and seat share is also included, its effect is insignificant and does not alter the other effects noticeably. The same holds true for Models 4 and 5.

26. Strictly speaking, the number of parties in the government should be taken into account in this model since the total payoff has to be divided more ways with each additional member party. This consideration turns out to be very minor, however, and does not affect the tenor of the results reported in the table. In fact, the pattern holds when the regression is performed separately on legislatures of different sizes (i.e., when the cases on each of the horizontal lines in Figure 3 are analyzed separately).

27. The formateur effect becomes negative and insignificant $(\beta=-0.007, S E=0.012)$ in Model 3, based on 351 cases. The seat share effect remains very powerful $(\beta=0.768$, $S E=0.033)$ and the voting weights effect weakens somewhat $(\beta=0.246, S E=0.048)$. In Models 4 and 5, the formateur effect assumes the correct (positive) sign, but remains insignificant.

28. The bargaining differential and formateur status together explain 29.1 per cent of the variance in the portfolio differential (both effects are significant at $p<0.05$ ). Another factor that may be involved is the policy preferences of parties; agrarian parties, e.g., may insist on the agricultural portfolio even if their size does not warrant it. The idea that parties assert claims for ministries of interest is most closely associated with Budge and Keman (1990). It is noteworthy, however, that they themselves do not attribute the small-party bias to it. Apart from lumpiness and a tendency for small parties to be rewarded for 'facilitating the emergence of a particular coalition', they follow Browne and Franklin (1973:461-463) in tracing the bias to generosity on the part of big parties who will dominate the coalition anyway (Budge \& Keman 1990: 130-131) - a proposition that would be very difficult to test.

29. Fréchette et al.'s (2005) experiments offer some support for Baron and Ferejohn's model; e.g., they find that a majority of proposals are accepted without delay, a majority of coalitions are minimal winning and bargaining power appears to be more important than voting weight (the equivalent of seat share in their design). While the proposer receives a relatively larger share than other coalition members, however, it remains the case that this share is substantially less than that predicted by the BaronFerejohn model. As with other experiments, it is unclear how relevant their design, which consisted of three subjects with different voting weights bargaining over a cash payoff in one session, is to real-world parliamentary bargaining. 
30. Baron and Ferejohn (1989), e.g., allow for an infinite number of sessions to reach a single agreement, but not for multiple agreements to be reached over time.

31. It is possible, of course, that none of the bargaining indices tested here adequately capture the concept of bargaining power. In fact, they have been subjected to a variety of criticisms (e.g., Gelman et al. 2003; Saari \& Sieberg 2000; Felsenthal \& Machover 1998). Note, however, that these measures tend to be theory-laden; e.g., legislative voting weights alone capture bargaining power as it is understood in most non-cooperative voting models (Ansolabehere et al. 2005: 552). To the extent that this is so, a finding that an index does not measure bargaining power appropriately would itself constitute a major challenge to the model or class of models in which it figures.

\section{References}

Ansolabehere, S. et al. (2005). Voting weights and formateur advantages in the formation of coalition governments. American Journal of Political Science 49: 550-563.

Baron, D. \& Ferejohn, J. (1989). Bargaining in legislatures. American Political Science Review 83: 1181-1206.

Browne, E. \& Franklin, M. (1973). Aspects of coalition payoffs in European parliamentary democracies. American Political Science Review 67: 453-469.

Browne, E.C. \& Feste, K. (1975). Qualitative dimensions of coalition payoffs: Evidence for European party governments, 1945-1970. American Behavioral Scientist 18: 530-556.

Browne, E.C. \& Frendreis, J.P. (1980). Allocating coalition payoffs by conventional norm: An assessment of the evidence from cabinet coalition situations. American Journal of Political Science 24: 753-768.

Budge, I. \& Keman, H. (1990). Parties and democracy: Coalition formation and government functioning in twenty states. Oxford: Oxford University Press.

Bueno de Mesquita, B. (1979). Coalition payoffs and electoral performance in European democracies. Comparative Political Studies 72: 61-81.

Druckman, J.N. \& Warwick, P.V. (2005). The missing piece: Measuring portfolio salience in Western European parliamentary democracies. European Journal of Political Research 44: 1-33.

Felsenthal, D.S. \& Machover, M. (1998). The measurement of voting power: Theory and practice, problems and paradoxes. Cheltenham: Edward Elgar.

Fréchette, G., Kagel, J.H. \& Lehrer, S.F. (2003). Bargaining in legislatures: An experimental investigation of open versus closed amendment rules. American Political Science Review 97: 221-232.

Fréchette, G., Kagel, J.H. \& Morelli, M. (2005). Nominal bargaining power, selection protocol and discounting in legislative bargaining. Journal of Public Economics.

Gamson, W. (1961). A theory of coalition formation. American Sociological Review 26: 373-382.

Gelman, A., Katz, J.N. \& Bafumi, J. (2003). Standard Voting Power Indexes Don't Work: An Empirical Analysis. Unpublished manuscript, Columbia University.

Harrington, J. (1990). The power of the proposal maker in a model of endogenous agenda formation. Public Choice 64: 1-20.

Huber, J. \& Inglehart, R. (1995). Expert interpretations of party space and party locations in 42 societies. Party Politics 1: 73-111.

Kennedy, P. (1998). A guide to econometrics (4th edn). Cambridge, MA: MIT Press. 
Laver, M. (1998). Models of government formation. Annual Review of Political Science 1: $1-25$.

Laver, M. \& Schofield, N. (1990). Multiparty government: The politics of coalition in Europe. Oxford: Oxford University Press.

Laver, M. \& Hunt, W.B. (1992). Policy and party competition. New York: Routledge.

Laver, M. \& Shepsle, K. (1996). Making and breaking governments. Cambridge: Cambridge University Press.

Leech, D. (2002). An empirical comparison of the performance of classical power indices. Political Studies 50: 1-22.

Lucas, W. (1978). Measuring power in weighted voting systems. In S. Brams, W. Lucas \& P. Straffin (eds), Political and related models. New York: Springer-Verlag.

Morelli, M. (1999). Demand competition and policy compromise in legislative bargaining. American Political Science Review 93: 809-820.

Müller, W. \& Strøm, K. (eds) (2000). Coalition governments in Western Europe. Oxford: Oxford University Press.

Narud, H.M. \& Valen, H. (2001). Coalition Membership and Electoral Performance in Western Europe. Paper presented at the Annual Meeting of the American Political Science Association, 30 August-2 September, San Francisco, CA.

Pajala, A., Meskanen, T. \& Kause, T. (2002). POWERSLAVE Power Index Calculator: A Voting Body Analyzer in the Voting Power and Power Index Website. Turku: University of Turku. Available online at: http://powerslave.val.utu.fi/.

Powell, G.B. Jr. (1982). Contemporary democracies: Participation, stability and violence. Cambridge, MA: Harvard University Press.

Rawlings, J.O., Pantula, S.G. \& Dickey, D.A. (1998). Applied regression analysis: A research tool (2nd edn). New York: Springer.

Rubinstein, A. (1982). Perfect equilibrium in a bargaining model. Econometrica 50: 97-109.

Saari, D.G. \& Sieberg, K.K. (2000). Some surprising properties of power indices. Games and Economic Behavior 36: 241-263.

Snedecor, G.W. \& Cochran, W.G. (1989). Statistical methods (8th edn). Ames, IA: Iowa State University Press.

Snyder, J.M., Ting, M.M. \& Ansolabehere, S. (2003). Legislative Bargaining under Weighted Voting. Unpublished manuscript, Massachusetts Institute of Technology.

Strauss, A., Ansolabehere, S. \& Snyder, J. (2003). Minimum integer weights and BaronFerejohn calculator. Cambridge, MA: MIT Press.

Warwick, P.V. \& Druckman, J.N. (2001). Portfolio salience and the proportionality of payoffs in coalition governments. British Journal of Political Science 38: 627-649.

Address for correspondence: Paul V. Warwick, Department of Political Science, Simon Fraser University, Burnaby, BC V5A 1S6, Canada. E-mail: warwick@sfu.ca 